\title{
HUBUNGAN ANTARA PENGETAHUAN PERAWATAN LUKA PASCA BEDAH SECTIO CAESAREA (SC) DENGAN TINGKAT KEMANDIRIAN PASIEN DI RUANG INSTALASI RAWAT INAP KEBIDANAN DAN KANDUNGAN RUMAH SAKIT BHAYANGKARA MANADO
}

\author{
Wahyuni Abd. Rahim \\ Sefti Rompas \\ Vandri D. Kallo \\ Program Studi Ilmu Keperawatan Fakultas Kedokteran \\ Universitas Sam Ratulangi \\ Email: wahyuniabd.rahim@gmail.com
}

\begin{abstract}
Caesarean section is defined as the birth of the fetus through an incision in the abdominal wall and uterine wall. The knowledge mother after giving birth with section caesarean regarding nursing determine the ability of the mother to take care of herself independently so that the mother is able to monitor change that occur in her after giving a birth. The purpose of this research was to determine the relationship between the knowledge of wound care postoperative caesarean section with the level of ndependance of patients in the obstetric and gynecology inpatient installation room at Bhayangkara Hospital, Manado. Research design of this research uses a type of descriptive research with a cross sectional approach. The number of samples were 32 people with purposive sampling technique. The data was collected using questionnaire and the analysis of the data using Fishers Exact statistical test. The results showed that the knowledge of wound care in postoperative caesarean section mothers was good (81,2\%), most of them had independent levels of independence $(65,6 \%)$ and were less independent $(34,4 \%)$ and where $p=0,011<0,05$. Conclusion there is a significant relationship between knowledge of wound care postoperative section caesarean with the level of independence of patients at the nursing room of the Bhayangkara Hospital, Manado.
\end{abstract}

Keywords: Wound Care, Caesarean Section, Level of Independence

Abstrak: Sectio caesarea didefinisikan sebagai lahirnya janin melalui insisi didinding abdomen dan dinding uterus. Pengetahuan ibu setelah melahirkan dengan sectio caesarea mengenai perawatan dapat menentukan kemampuan ibu dalam merawat diri secara mandiri sehngga ibu mampu memantau perubahan yang terjadi pada dirinya setelah melahirkan. Tujuan penelitian ini bertujuan untuk mengetahui hubungan antara pengetahuan perawatan luka pasca bedah sectio caesarea dengan tingkat kemandirian pasien di ruang Instalasi Rawat Inap Kebidanan dan Kandungan RS Bhayangkara Manado. Desain Penelitian jenis penelitian ini menggunakan jenis penelitian deskriptif dengan pendekatan cross sectional. Jumlah sampel 32 orang dengan menggunakan teknik sampel purposive sampling. Alat pengumpulan datas berupa kuesioner. Analisa data menggunakan uji statistik Fishers Excat. Hasil Penelitian didapatkan bahwa pengetahuan perawatan luka pada ibu pasca bedah sectio caesarea baik $(81,2 \%)$, sebgaian besar memiliki tingkat kemandirian mandiri $(65,6 \%)$ dan kurang mandiri $(34,4 \%)$ dan dimana $p=0,011<0,05$. Kesimpulan terdapat hubungan yang signifikan antara pengetahuan perawatan luka pasca bedah sectio caesarea dengan tingkat kemandirian pasien di ruang instalasi rawat RS Bhayangkara Manado.

Kata Kunci: Perawatan Luka, Sectio Caesarea, Tingkat Kemandirian 


\section{PENDAHULUAN}

Persalinan bisa terjadi secara fisiologis maupun patologis. Persalinan patologis kadang membutuhkan tindakan pembedahan (sectio caesarea). Sectio caesarea didefinisikan sebagai lahirnya janin melalui insisi di dinding abdomen (laparatomi) dan dinding uterus (histerektomi) (Cunningham, 2006). Angka kejadian sectio caesarea di Indonesia menurut Survei Demografi dan Kesehatan Indonesia (SDKI) tahun 2007 adalah 921.000 dari 4.039.000 persalinan atau sekitar $22,8 \%$ dari seluruh persalinan, angka ini lebih tinggi dan meningkat drastis bila dibandingkan pada tahun 1997 yang hanya $4,1 \%$ persalinan yang berakhir dengan sectio caesarea, yaitu sebanyak 695 kasus dari 16.217 persalinan (Kemenkes RI, 2011).

Persalinan melalui sectio caesarea tetap mengandung resiko dan kerugian yang lebih besar, resiko kematian dan komplikasi lebih besar seperti resiko kesakitan dan menghadapi masalah fisik pasca operasi yang menimbulkan rasa sakit, perdarahan, infeksi, kelelahan, sakit punggung, sembelit dan gangguan tidur juga memiliki masalah secara psikologis karena kehilangan kesempatan untuk berinteraksi dengan bayi dan merawatnya (Depkes RI, 2006).

$\begin{array}{ccc}\text { Badan } & \text { Kesehatan } & \text { Dunia } \\ \text { merekomendasikan } & \text { bahwa } & \text { angka }\end{array}$
persalinan dengan tindakan sectio caesarea pada ibu hamil tidak boleh lebih dari 10$15 \%$. Prosedur operasi sectio caesarea di Inggris menyebabkan infeksi luka sebesar 5\% (The National Institute for Health and Clinical Excellence, 2008). Infeksi luka operasi merupakan luka yang disebabkan karena prosedur sectio invasif. Infeksi luka operasi bisa menyebabkan kecacatan dan kematian (Gould, 2012). Infeksi luka pasca operasi merupakan salah satu masalah utama dalam praktek pembedahan. Dengan berkembangnya era asepsis, teknik operasi serta perawatan bedah maka komplikasi luka pasca operasi cenderung menurun, jika luka pasien mengalami infeksi menyebabkan masa perawatan lebih lama
(Marison, 2004).Kejadian infeksi luka operasi di rumah sakit Inggris tahun 2006 sebesar 13,8 luka operasi yang di dapat ibu salah satunya melalui operasi sectio caesarea. (World Health Organization, 2010).

Banyak wanita yang cemas akan rasa sakit dalam menghadapi persalinan normal, sehingga banyak yang memilih melakukan operasi sectio caesarea walaupun tanpa indikasi apapun dengan alasan lebih praktis. Di Indonesia persentase operasi sectio caesarea sekitar 5\%. (Dewi, 2012). Tingginya angka kelahiran dengan sectio caesarea memungkinkan ibu beresiko besar mengalami komplikasi, apabila tidak dilakukan perawatan yang benar seperti tidak menjaga kebersihan diri serta pola makan yang tidak teratur. Selain itu persalinan sectio caesarea dapat berdampak pada timbulnya komplikasi seperti infeksi puerperalis, trauma kandung kemih dan gangguan mobilisasi (Wiknjosastro, 2008).

Tindakan sectio caesarea juga berdampak pada pemenuhan kebutuhan dasar ibu seperti dapat menyebabkan nyeri pada bekas luka operasi, gangguan eliminasi urin, gangguan pemenuhan nutrisi dan cairan, gangguan aktifitas, gangguan personal hygiene, gangguan pola istirahat dan tidur serta masalah dalam produksi dan pemberian air susu ibu pada bayinya (Maryunani, 2015). Kemampuan merawat diri ibu setelah melahirkan sangat penting untuk meningkatkan status kesehatan ibu. Pengetahuan dan sikap ibu setelah melahirkan dengan sectio caesarea mengenai perawatan dapat menentukan kemampuan ibu dalam merawat diri secara mandiri sehingga ibu mampu memantau perubahan-perubahan yang terjadi pada dirinya, mempertahankan kesehatannya dan mengambil keputusan yang tepat bila terjadi masalah-masalah selama masa setelah melahirkan.

Perawatan luka telah mengalami perkembangan yang sangat pesat. Teknologi dalam bidang kesehatan juga memberikan kontribusi yang sangat untuk menunjang praktek perawatan luka ini. 
Dengan demikian, perawat di tuntut untuk mempunyai pengetahuan dan keterampilan yang adekuat terkait dengan proses perawatan luka yang dimulai dari pengkajian yang komprehensif, perencanaan intervensi yang tepat, implementasi tindakan, evaluasi hasil yang ditemukan selama perawatan serta dokumentasi hasil yang sistematis (Agustina, 2015).

Hasil survei awal penulis memperoleh data dari ruang Instalasi Rawat Inap Kebidanan dan Kandungan RS Bhayangkara Manado jumlah pasien melakukan perawatan luka pasca bedah sectio caesarea yaitu sebanyak 81 pasien pada periode bulan April sampai dengan Juni 2018. Pada tanggal 12 Juli 2018 dilakukan wawancara di ruang Instalasi Rawat Inap Kebidanan dan Kandungan RS Bhayangkara Manado pada 3 pasien pasca bedah sectio caesarea, 2 orang pasien tidak mempunyai pengetahuan tentang perawatan luka pasca bedah sectio caesarea dan kemandiriannya, sedangkan 1 orang pasien lainnya mempunyai pengetahuan perawatan luka pasca bedah sectio caesarea dan kemandiriannya.

Berdasarkan latar belakang di atas, peneliti termotivasi untuk melakukan penelitian tentang hubungan antara pengetahuan perawatan luka pasca bedah sectio caesarea dengan tingkat kemandirian pasien pasien di ruang Instalasi Rawat Inap Kebidanan dan Kandungan RS Bhayangkara Manado.

\section{METODE PENELITIAN}

Rancangan penelitian ini adalah kuantitatif dengan studi deskriptif korelasi yaitu suatu desain untuk mengkaji hubungan antara variabel (Nursalam, 2008). Desain penelitian yang digunakan adalah metode cross sectional, dimana hubungan antara pengetahuan perawatan luka pasca bedah sectio caesarea (variabel independen) dengan tingkat kemandirian pasien (variabel dependen) dilihat dan diukur satu kali dalam waktu bersamaan. Penelitian ini telah dilakukan di ruang
Instalasi Rawat Inap Kebidanan dan Kandungan RS Bhayangkara Manado pada tanggal 22 November - 06 Desember 2018.

Populasi dalam penelitian ini sebanyak 27 orang perbulan. Teknik pengambilan sampel ditentukan dengan rumus purposive sampling sehingga sampel yang digunakan dalam penelitian ini berjumlah 32 orang. Instrumen pada penelitian ini menggunakan kuesioner. Pada bagian pertama instrumen penelitian berisi data karakteristik responden yang terdiri dari nama responden, umur, pendidikan, pekerjaan, dan variabel independen yaitu pengetahuan yang terdiri dari 12 pernyataan dengan nilai median 6 dan bobot jawaban jika benar maka skor 1 dan jika salah maka skor 0. Pada bagian kedua instrumen penelitian berisi data karakteristik responden yang terdiri dari nama responden, umur, pendidikan, pekerjaan, dan variabel dependen yaitu tingkat kemandirian yang terdiri dari 8 pernyataan dengan nilai median 16 dan bobot jawaban jika benar maka skor 3 dan jika salah maka skor 1 .

Teknik analisa data yang digunakan pada penelitian ini yaitu analisa univariat dan analisa bivariat. Analisa univariat pada penelitian ini bertujuan untuk mendeskripsikan setiap variabel diantaranya pengetahuan perawatan luka dan tingkat kemandirian. Sedangkan analisa bivariat dilakukan terhadap dua atau lebih variabel yang diduga memiliki korelasi, yaitu pengetahuan perawatan luka dan tingkat kemandirian, dengan menggunakan uji statistik Fishers Exact pada tingkat kepercayaan $95 \%(\alpha \leq 0.05)$.

Etika penelitian bertujuan untuk menjaga kerahasiaan identitas responden akan kemungkinan terjadi ancaman terhadap responden. Etika penelitian berguna sebagai pelindung terhadap institusi tempat penelitian dan peneliti itu sendiri (Nursalam, 2008). 
HASIL dan PEMBAHASAN

Tabel 1. Distribusi frekuensi berdasarkan umur

\begin{tabular}{ccc}
\hline Umur & $\mathbf{n}$ & $\mathbf{( \% )}$ \\
\hline $18-26$ tahun & 11 & 34,4 \\
$27-35$ tahun & 21 & 65,6 \\
\hline Total & $\mathbf{3 2}$ & $\mathbf{1 0 0 , 0}$ \\
\hline
\end{tabular}

Sumber: Data Primer 2018

Berdasarkan tabel 1, distribusi diatas, umur responden terbanyak pada kelompok umur 27 - 35 tahun yaitu sebanyak 21 orang $(65,5 \%)$, sedangkan yang paling sedikit yaitu umur $18-26$ tahun sebanyak 11 orang $(34,4 \%)$.

Tabel 2. Distribusi frekuensi berdasarkan pendidikan

\begin{tabular}{ccc}
\hline Pendidikan & $\mathbf{n}$ & $\mathbf{( \% )}$ \\
\hline SD & 1 & 3,1 \\
SMP & 8 & 25,0 \\
SMA/Sederajat & 15 & 46,9 \\
D3/S1 & 8 & 25,0 \\
\hline Total & $\mathbf{3 2}$ & $\mathbf{1 0 0 , 0}$ \\
\hline
\end{tabular}

Sumber: Data Primer 2018

Berdasarkan tabel 2, distribusi diatas, pendidikan responden terbanyak berpendidikan SMA/Sederajat yaitu sebanyak 15 orang $(46,9 \%)$ dan yang paling sedikit berpendidikan SD yaitu sebanyak 1 orang $(3,0 \%)$.

Tabel 3. Distribusi frekuensi berdasarkan pekerjaan

\begin{tabular}{ccc}
\hline Pekerjaan & n & $(\boldsymbol{\%})$ \\
\hline PNS & 4 & 12,5 \\
Wiraswasta & 2 & 6,3 \\
Honorer & 4 & 12,5 \\
IRT & 22 & 68,8 \\
\hline Total & $\mathbf{3 2}$ & $\mathbf{1 0 0 , 0}$ \\
\hline
\end{tabular}

Sumber: Data Primer 2018

Berdasarkan tabel 3, distribusi diatas, pekerjaan responden terbanyak bekerja sebagai IRT yaitu sebanyak 22 orang $(68,8 \%)$ dan paling sedikit bekerja sebagai Wiraswasta yaitu sebanyak 2 orang $(6,3 \%)$.
Tabel 4. Distribusi frekuensi berdasarkan pengetahuan perawatan luka

\begin{tabular}{ccc}
\hline $\begin{array}{c}\text { Pengetahuan } \\
\text { Perawatan Luka }\end{array}$ & n & $(\boldsymbol{\%})$ \\
\hline Baik & 26 & 81,2 \\
Kurang Baik & 6 & 18,8 \\
\hline Total & $\mathbf{3 2}$ & $\mathbf{1 0 0 , 0}$ \\
\hline
\end{tabular}

Sumber: Data Primer 2018

Berdasarkan tabel 4,hasil penelitian diperoleh gambaran pengetahuan perawatan luka baik sebanyak 26 orang $(81,2 \%)$, sedangkan pengetahuan perawatan luka kurang baik sebanyak 6 orang $(18,8 \%)$.

Tabel 5. Distribusi frekuensi berdasarkan tingkat kemandirian

\begin{tabular}{ccc}
\hline Tingkat Kemandirian & $\mathbf{n}$ & $(\boldsymbol{\%})$ \\
\hline Mandiri & 21 & 65,6 \\
Kurang Mandiri & 11 & 34,4 \\
\hline Total & $\mathbf{3 2}$ & $\mathbf{1 0 0 , 0}$ \\
\hline
\end{tabular}

Sumber: Data Primer 2018

Berdasarkan tabel 5, hasil penelitian diperoleh gambaran tingkat kemandirian mandiri sebanyak 21 orang $(65,6 \%)$, sedangkan tingkat kemandirian kurang mandiri sebanyak 11 orang $(34,4 \%)$.

Tabel 6. Analisis hubungan antara pengetahuan perawatan luka pasca bedah sectio caesarea dengan tingkat kemandirian pasien

\begin{tabular}{|c|c|c|c|c|c|c|c|}
\hline \multirow{3}{*}{$\begin{array}{c}\text { Pengetahuan } \\
\text { perawatan } \\
\text { luka }\end{array}$} & \multicolumn{6}{|c|}{ Tingkat kemandirian } & \multirow{3}{*}{$\begin{array}{c}\mathrm{P} \\
\text { Value }\end{array}$} \\
\hline & \multicolumn{2}{|c|}{ Mandiri } & \multicolumn{2}{|c|}{$\begin{array}{l}\text { Kurang } \\
\text { mandiri }\end{array}$} & \multicolumn{2}{|c|}{ Total } & \\
\hline & $\mathrm{n}$ & $\%$ & $\mathrm{n}$ & $\%$ & $\mathrm{n}$ & $\%$ & \\
\hline Baik & 20 & 76,9 & 6 & 23,1 & 26 & 100 & \multirow{3}{*}{0,011} \\
\hline Kurang baik & 1 & 16,7 & 5 & 83,3 & 6 & 100 & \\
\hline Total & 21 & 65,6 & 11 & 34,4 & 32 & 100 & \\
\hline
\end{tabular}

Sumber: Data Primer 2018

Berdasarkan tabel 6 , hasil penelitian diperoleh gambaran pengetahuan perawatan luka baik sebanyak 26 orang sedangkan pengetahuan perawatan luka kurang baik sebanyak 6 orang dan 
gambaran tingkat kemandirian mandiri sebanyak 21 orang, sedangkan tingkat kemandirian kurang mandiri sebanyak 11 orang. Hasil analisis statistik menggunakan uji Fishers Exact Test menunjukan nilai $p$ $=0,011$. Tingkat kepercayaan alfa $(\alpha)$ yang digunakan yaitu: 0,05 . Jadi $p<\alpha=0,05$ sehingga Ho ditolak artinya terdapat hubungan yang signifikan.

\section{Umur}

Berdasarkan hasil penelitian didapatkan bahwa sebagian besar umur responden terbanyak berumur $27-35$ tahun yaitu $65,6 \%$. Pada teori yang dikemukakan oleh Notoatmodjo (2005) yang menyatakan umur yang matang sangat bepengaruh positif terhadap pencapaian pengetahuan seseorang. Umur mempengaruhi daya tangkap dan pola pikir seseorang terhadap informasi yang diberikan.

\section{Pendidikan}

Penelitian didapatkan bahwa sebagian besar pendidikan responden terbanyak berpendidikan SMA/Sederajat yaitu 46,9\%. Pendidikan sangat erat hubungannya dengan pengetahuan. Tingkat pendidikan akan membantu dalam memperoleh pengetahuan, pemahaman, serta nilai-nilai lainnya yang akan membantu untuk berpikir lebih rasional dalam memyarap informasi. Pengetahuan yang baik dapat disebabkan karena mereka mendapat informasi dari luar melalui interaksi sosial seperti arisan, pertemuan antar warga, televisi, sosial media, dan lain-lain.

\section{Pekerjaan}

Hasil penelitian ini didapatkan bahwa sebagian besar pekerjaan responden terbanyak bekerja sebagai ibu rumah tangga yaitu $68,8 \%$. Lingkungan pekerjaan dapat menjadikan seseorang memperoleh pengalaman baik secara langsung maupun tidak langsung. Interaksi dengan lingkungan serta informasi dari media massa elektronik akan membantu seseorang mendapatkan informasi yang akan mempengaruhi pengetahuan menjadi lebih baik.

\section{Pengetahuan Perawatan Luka}

Berdasarkan penelitian yang dteliti diperoleh gambaran pengetahuan perawatan luka yang baik sebanyak 26 orang, sedangkan pengetahuan perawatan luka yang kurang baik sebanyak 6 orang. Hasil penelitian ini sejalan dengan penelitian yang dilakukan oleh Maria (2016) yang menunjukan bahwa sebanyak $74 \%$ pengetahuan ibu tentang perawatan luka pasca bedah sectio caesarea dalam kategori baik. Pengetahuan dipengaruhi oleh berbagai faktor yang terjadi disekitar kita baik faktor internal maupun eksternal. Faktor internal yaitu dari pengalaman pribadi dan faktor eksternal yaitu dari pengalaman orang lain serta dipengaruhi oleh tingkat pendidikan dan umur yang dapat mengetahui informasi tentang operasi sectio caesarea, informasi dari berbagai sumber seseorang dapat memperoleh pengetahuan yang luas.

Tingkat pengetahuan baik adalah seseorang mampu mengetahui perilaku yang didasari oleh pengetahuan yang baik, maka akan terbentuk kesadaran dan sikap yang positif (Arikunto, 2006). Hal ini menunjukan bahwa dengan pengetahuan yang baik tentang perawatan luka pasca bedah sectio caesarea ibu mengetahui halhal yang berhubungan dengan perawatan luka sectio caesarea sehingga terbentuk kesadaran dan sikap yang positif.

\section{Tingkat Kemandirian}

Gambaran tingkat kemandirian dari hasil penelitian yang didapat yaitu mandiri sebanyak 21 orang, sedangkan tingkat kemandirian yang kurang mandiri sebanyak 11 orang. Hasil penelitian ini sejalan dengan hasil penelitian Putinah (2014) yang menyatakan sebagian besar ibu pasca bedah sectio caesarea mandiri dengan baik. Faktor yang mempengaruhi kemandirian yaitu pengalaman, sesuatu yang pernah dilakukan dapat menambah pengalaman seseorang tentang suatu hal. Pada penelitian 
ini sebagian besar pasien mandiri pasca bedah sectio caesarea disebabkan karena sebagian besar ibu bersalin telah melahirkan lebih dari 1 kali, artinya sebelumnya pernah bersalin sehingga ibu sudah memiliki pengalaman sebelumnya. Sectio caesarea sering menimbulkan ketidakmandirian dari pasien itu sendiri. Karena sakit yang ditimbulkan oleh operasi, pasien merasa lemah dan kurang aktifitas. Ada beberapa hal yang menyebabkan seseorang itu kurang mandiri disebabkan kerena salah satunya adalah rasa nyeri akibat tindakan sectio caesarea, karena adanya rasa sakit/nyeri dapat menjadi alasan untuk bergerak lebih lamban.

\section{Hubungan Antara Pengetahuan Perawatan Luka Pasca Bedah Sectio Caesarea dengan Tingkat Kemandirian Pasien di Ruang Instalasi Rawat Inap Kebidanan dan Kandungan RS Bhayangkara Manado}

Hasil analisis statistik menggunakan uji Fishers Exact menunjukan nilai $p=$ 0,011 dimana nilai $p$ lebih kecil dari nilai $(\alpha)$ : 0,05 yang menunjukan bahwa terdapat hubungan antara pengetahuan perawatan luka pasca bedah sectio caesarea dengan tingkat kemandirian pasien, karena semakin banyak pengetahuan baik bagi ibu pasca bedah sectio caesarea semakin banyak ibu mandiri dalam perawatan luka.

Berdasarkan hasil penelitian diperoleh sebagian besar pasien mempunyai pengetahuan perawatan luka baik, didapatkan hasil tingkat kemandirian pasien mandiri. Adapun faktor yang diperoleh oleh peneliti bahwa pengetahuan perawatan luka yang baik merupakan didasari oleh pengetahuan yang baik sehingga terbantuk kesadaran dan pola pikir untuk melakukan perawatan luka yang baik, didapatkan faktor-faktor yang menunjang pengetahuan perawatan luka pasca bedah sectio caesarea yaitu memakan makanan yang mengandung nutrisi yang baik, melakukan mobilisasi/aktivitas kecil, istirahat dan tidur yang cukup, menjaga personal hygiene dan aktifitas mandiri lainnya.
Kebutuhan perawatan diri pada pasien pasca bedah sectio caesarea selain pemenuhan istirahat dan tidur juga pemenuhan kebersihan diri (personal hygiene). Kebersihan diri setelah melahirkan secara sectio caesarea terutama meliputi kebersihan dalam perawatan luka sectio caesarea bertujuan untuk mencegah timbulnya infeksi, menjaga luka dari trauma, menigkatkan proses penyembuhan luka dan mencegah masuknya bakteri. Selain itu aktifitas dan latihan / mobilisasi pasca bedah sectio caesarea adalah suatu pergerakan, posisi atau adnya kegiatan yang dilakukan ibu setelah beberapa jam melahirkan dangan persalianan sectio caesarea.

Penelitian ini terdapat 6 responden memiliki pengetahuan baik tetapi kurang mandiri, disebabkan karena pasien tersebut ada beberapa yang baru pertama kali melahirkan sehingga pasien belum mampu melakukan aktifitasnya sendiri dan harus dibantu oleh orang lain. Dan terdapat 1 responden yang memiliki pengetahuan kurang baik tetapi mandiri ini disebabkan karena faktor umur, dimana pasien tersebut berumur sudah diatas 30 tahun tapi baru pertama kali melahirkan dan pada saat diteliti pasien tersebut sudah terlihat melakukan aktifitasnya sendiri tanpa bantuan orang lain. Oleh sebab itu ketika seseorang yang memiliki pengetahuan baik maka terbentuklah sikap mandiri dalam melakukan segala hal. Namun pada sebagian orang walaupun memiliki pengetahuan ada beberapa diantaranya kurang mandiri seperti kurangnya asupan nutrisi, vitamin dan mineral yang cukup, kurangnya menjaga kebersihan diri, serta kurangnya mobilisasi akibat adanya rasa sakit/nyeri yang menjadi alasan untuk tidak bergerak.

\section{SIMPULAN}

1. Gambaran pengetahuan perawatan luka pasca bedah sectio caesarea di ruang Instalasi Rawat Inap Kebidanan dan Kandungan RS Bhayangkara Manado adalah baik. 
2. Gambaran tingkat kemandirian pasien di ruang Instalasi Rawat Inap Kebidanan dan Kandungan RS Bhayangkara Manado adalah mandiri.

3. Terdapat hubungan yang signifikan antara hubungan antara pengetahuan perawatan luka pasca bedah sectio caesarea dengan tingkat kemandirian pasien di ruang Instalasi Rawat Inap Kebidanan dan Kandungan RS Bhayangkara Manado.

\section{DAFTAR PUSTAKA}

Arikunto, S. (2006).Prosedur Penelitian Suatu Pendekatan Praktik. Jakarta: Rineka Cipta

Agustina, H. R. 2015. Manajemen perawatan luka modern.

Cunningham, F.G.,N.F., Leveno, K.J., Gilstrap, L.C., Hauth, J.C.\& Wenstrom, K.D (2006) William Obstetrics, (21sted). United States of Amerika: Mc Graw-Hill Companies, Inc.

Depkes RI. 2006. Pedoman Penyelenggaraan dan Prosedur Rekam Medis Rumah Sakit di Indonesia. Jakarta: Depkes RI.

Dewi, S. 2012. Efektifitas Pendidikan Kesehatan tentang Nutrisi dan Perawatan Luka dengan Video terhadap Penyembuhan Luka Sesarea.Tesis. Jakarta: Program Keperawatan Universitas Indonesia.

Gould, D. 2012. Causes, Prevention and Management of Surgical Site Infection. Nursing standard. 26: 4756.

Kemenkes RI, 2011, Profil Kesehatan Indonesia 2010, Jakarta: Kementerian Kesehatan RI.

Maryunani.(2015). Asuhan Keperawatan Maternitas. Jakarta: Salemba Medika
Maria, P. M. (2016). Hubungan Pengetahuan Ibu Tentang Luka Sectio Caesarea dengan Penyembuhan Luka Post Sectio Caesarea di Poliklinik Kebidanan dan Kandungan RSUD Kota Surakarta.

Morison, M.J. (2004). Manajemen Luka. Jakarta: EGC.

Nursalam. (2008). Konsep dan penerapan metodologi penelitian ilmu keperawatan: pedoman skripsi, tesis, dan instrumen penelitian keperawatan. Jakarta : Salemba Medika

Notoatmojo, (2005).Metodologi Penelitian Kesehatan. Jakarta : Rineka Cipta.

Putinah. (2014). Faktor-faktor yang berhubungan dengan kemandirian ibu post Sectio Caesaria di Rumah Sakit Islam Siti Khadijah Palembang, Jurnal Keperawatan Bina Husada.

The National Institute for Health and Clinical Excellence (NICE). 2008Surgical Site Infection: Prevention and Treatment of Surgical Site Infection Clinical Guideline. National Collaborating Centre Women'sand Children's Health

World Health Organization (WHO). 2010. Caesarea Sectio without Medical indication increases Risk of Shortterm adverse outcomes for mothers. Bull WHO Reproductive Health and Research.

Wiknjosastro, Hanifa. (2008). Ilmu Kandungan. Edisi 2.EGC : Jakarta. 